\title{
Method for achieving hydraulic balance in typical Chinese building heating systems by managing differential pressure and flow
}

Zhang, Lipeng; Xia, Jianjun; Thorsen, Jan Eric; Gudmundsson, Oddgeir; Li, Hongwei; Svendsen, Svend

Published in:

Building Simulation

Link to article, DOI:

10.1007/s12273-016-0307-2

Publication date:

2017

Document Version

Peer reviewed version

Link back to DTU Orbit

Citation (APA):

Zhang, L., Xia, J., Thorsen, J. E., Gudmundsson, O., Li, H., \& Svendsen, S. (2017). Method for achieving hydraulic balance in typical Chinese building heating systems by managing differential pressure and flow. Building Simulation, 10(1), 51-63. https://doi.org/10.1007/s12273-016-0307-2

\section{General rights}

Copyright and moral rights for the publications made accessible in the public portal are retained by the authors and/or other copyright owners and it is a condition of accessing publications that users recognise and abide by the legal requirements associated with these rights.

- Users may download and print one copy of any publication from the public portal for the purpose of private study or research.

- You may not further distribute the material or use it for any profit-making activity or commercial gain

- You may freely distribute the URL identifying the publication in the public portal 


\title{
Method for achieving hydraulic balance in typical Chinese building heating systems by managing differential pressure and flow
}

\begin{abstract}
Hydraulic unbalance is a common problem in Chinese district heating (DH) systems. Hydraulic unbalance has resulted in poor flow distribution among heating branches and overheating of apartments. Studies show that nearly $30 \%$ of the total heat supply is being wasted in Chinese DH systems due to a lack of pressure and flow control. This study investigated using pre-set radiator valves combined with differential pressure (DP) controllers to achieve hydraulic balance in building distribution systems, and consequently save energy and reduce the emissions. We considered a multi-storey building modelled in the IDA-ICE software, along with a self-developed mathematical hydraulic model to simulate its heat performance and hydraulic performance with various control scenarios. In contrast to the situation with no pressure or flow control, this solution achieves the required flow distribution and close-to-design room temperatures, as well as $16 \%$ heat savings, $74 \%$ pump electricity savings, and proper cooling of supply water. The energy consumption savings would therefore have positive environmental impacts, and be reflected in seasonal reductions of $2.1 \mathrm{~kg} / \mathrm{m}^{2} \mathrm{CO}_{2}, 0.02 \mathrm{~kg} / \mathrm{m}^{2} \mathrm{SO}_{2}$, and $0.01 \mathrm{~kg} / \mathrm{m}^{2} \mathrm{NO}_{\mathrm{x}}$ for $3^{\text {rd }}$ step energy efficiency buildings in Beijing.
\end{abstract}

Key words: district heating, hydraulic balance, differential pressure controller, pre-set radiator valve, pressure and flow control, IDA-ICE

\section{Introduction}

\subsection{Background}

Research studies have indicated that DH (district heating) has a key role to play in society's goal of achieving an effective and sustainable energy system (Xia et al. 2016; Lund et al. 2010; Lund et al. 2014; Yang et al. 2016). With its rapid growth in urbanization and industrialization, China has become one of the largest DH markets in the world in the last two decades. Statistics indicate that the total DH production in 2013 amounted to 3,197,032 TJ (EURO HEAT \& POWER 2013). This number is still increasing steadily due to the process of rapid urbanization, the expansion in the total building area, the enhancement of building services, and increases in requirements for comfort. The development of DH in high-population and cold climate regions has become an environmentally friendly and energy-efficient strategy for ensuring energy supply security and air pollution abatement, which are the two most important challenges facing China today (Hong et al. 2013; Lin and Liu 2015; Chen et al. 2013). Enhancing the efficiency of DH systems by modernizing them is particularly critical. One of the main issues influencing the efficiency of Chinese DH systems is the energy wasted due to hydraulic unbalances in the systems. The failure to install control devices to enable pressure and flow control in the DH network has resulted in poor flow distribution among heating branches, and consequently nearly $30 \%$ of the total heat supply is being wasted through excess flow and overheating of apartments (Building Energy Research Center of Tsinghua University 2011; Yan et al. 2011a).

Multi-storey and high-rise buildings are typical in China. Pressurized hot water as the heat medium is produced at a heat source and is directly transmitted to a number of high-rise or multi-storey buildings via heat entrances. In some cases, area substations indirectly exchange the heat from the primary network (from heat source to area substations) to secondary network (from area substation to buildings), which then enters the building heating 
systems via the heat entrance. The heat entrance is the interface between the DH system and the building heating system and is generally equipped with shut-off valves, a strainer, thermometers, pressure gauges, a heat meter, etc. Moreover, the national design code emphasizes a two-pipe radiator system, with each apartment having its own heating loop, as the primary form of SH (space heating) system in future multi-storey buildings in China (Liu et al. 2015).

Establishing a hydraulic balance is a matter of controlling the DP (differential pressure) to the required level, thereby controlling the flow rate in individual branches. In practice, the most common adjustment devices in current Chinese DH systems are the manual balancing valves installed at building heat entrances to limit the flow through the buildings. They are relatively inexpensive to install, but the system-commissioning work is complex and time-consuming. On the other hand, against the background of the implementation of heat reforms in China, the application of TRVs (thermostatic radiator valves) in DH systems has become more common (Xu et al. 2008). For instance, in 2006, $16 \%$ of the total heating area in China was given a heat metering retrofit (Zhang et al. 2013) to install TRVs. However, the use of TRVs transforms a constant flow heating system into a variable flow system. This can cause problems in systems that continue to use manual balancing valves, because they rely on static conditions and cannot cope with the system changes introduced by the TRVs. This means that an effective solution that uses appropriate control devices to achieve hydraulic balance in multi-storey building heating systems is urgently needed.

There have been a lot of studies on improving the efficiency of Chinese DH systems that have focused on various DH elements(Fang et al. 2013a; Sun et al. 2012; Fang et al. 2013b; Wang et al. 2011; Jing et al. 2014; Jie et al. 2015; Jiang et al. 2014; Jie et al. 2012; Cao et al. 2014; Wang et al. 2011). Some studies have investigated the control strategies used in relation to hydraulic balance issues in Chinese DH systems (Yan et al. 2013; Ma and Wang 2009). For instance, Yan et al. (2013) proposed improving hydraulic performance by using variable speed distributed pumps on the primary side of indirectly connected DH systems. Moreover, with the implementation of heat reform in China, research has also been carried out on TRV application in Chinese heating systems (Xu et al. 2008; Xu et al. 2013; Li et al. 2009; Yan et al. 2011b; Liu et al. 2011; Xu et al. 2009; $\mathrm{Xu}$ et al. 2014). Xu et al. (2009) investigated how the regulation of TRVs and the opening of windows influenced the hydraulic performance and energy consumption of a DH system. Xu et al. (2008) studied the thermal and hydraulic behaviour of SH systems that use TRV-controlled radiators in multi-family buildings. Xu et al. (2014) carried out a survey of district heating systems in northern China and verified the fact that hydraulic unbalance due to poor levels of control and monitoring in DH systems results in wasted energy or excessive heat supply.

However, when we examine the previous research mentioned above, there is still a lack of expertise or knowledge on how building heating systems can be optimized by correctly using flow control and temperature control and, not least, their inherent relationship with energy savings and indoor temperature improvement.

This paper presents a technical concept that combines the use of DP controllers and pre-set radiator valves to control the pressure and flow in two-pipe multi-storey building heating systems. The current popularity of TRVs in China makes it possible to adjust individual local radiators, but the flow pre-setting function of radiator valves and the benefits of DP controllers are not well understood. A clear understanding of the technical concept will help to further support and promote relevant policies targeted at enabling and improving the energy efficiency of 
buildings in China. This could give enhanced understanding and guidance for renovating future Chinese DH systems.

\subsection{Current situation from a real case}

To make it possible to understand the current hydraulic situation in Chinese multi-storey building heating systems, we present data from a real heating system in Beijing, China (CASE-Beijing). These data were used to analyse the hydraulic performance of this actual heating system. They were not used in the later simulation.

\subsubsection{Basic information}

The CASE-Beijing heating system supplies heat to 25 multi-storey/high-rise residential buildings, with a total heating are of nearly $278,000 \mathrm{~m}^{2}$ (Figure 1). As the heat-carrying medium, hot water is produced at central gasfired boilers and transported to those 25 buildings via 31 heat entrances. Manual balancing valves are installed at the heat entrances to manage the water flow into the connected buildings. DH utilities usually use a flow index to determine the required volume flow to each building in accordance with the heating area served. The manual balancing valves are set at the beginning of the heating season in accordance with this estimated flow and the DP across the controlled loop. After this initial commissioning, the settings of these manual balancing valves are kept for the complete heating season, except for minor adjustments. Moreover, no control devices are applied to regulate the flow distribution between the apartments within the building.

All the buildings in this area were built in 2005 with the same exterior envelope materials. The buildings meet the requirements of the $3^{\text {rd }}$ step of the energy efficiency building standard for Beijing. According to this standard, the peak heat load of those buildings is required to be no more than $32 \mathrm{~W} / \mathrm{m}^{2}$ under a design outdoor temperature of $-9{ }^{\circ} \mathrm{C}$ for the heating period, and the average heat loss index is required to be no more than $14.15 \mathrm{~W} / \mathrm{m}^{2}$ under an average outdoor temperature of $0{ }^{\circ} \mathrm{C}$ during the heating period of 120 days (Zhang et al. 2015). This implies the seasonal heat consumption per square metre of the buildings in CASE-Beijing is $0.15 \mathrm{GJ} / \mathrm{m}^{2}$. For this case, the initial design temperatures for the radiator heating system were $75 / 50 / 18{ }^{\circ} \mathrm{C}$ (supply/return/indoor temperature, while the system operates as constant flow. This means that the design flow rate per $\mathrm{m}^{2}$ can be calculated to be $1.1 \mathrm{~kg} / \mathrm{m}^{2} \cdot \mathrm{h}$.

\subsubsection{Data analysis}

First, the mass flows were measured using an ultrasonic flow meter. The mass flows per square metre for all 31 heat entrances can be calculated based on the heated area. The results are shown in Figure 2. These data reflect the water flow through the 31 heat entrances and into the 25 connected buildings via the horizontal pipelines.

Since the interior envelopes of all the buildings were characterized as having the same insulation properties and the heating system operates on the constant flow principle, the unit mass flow should theoretically be numerically equal or similar for all the heat entrances. Compared to the design unit mass flow, 27 out of 31 heat entrances are in a state of excess flow, and the unit mass flow through all 31 heat entrances is uneven. These data show that there is hydraulic unbalance in the DH distribution network.

Next, to investigate the vertical flow distribution, one of the high-rise buildings was selected for measurement of the mass flows along the internal vertical riser. The building chosen was \#3, with 21 stories. Figure 3 illustrates the mass flow per square metre along the low-pressure riser at the $1^{\text {st }}, 6^{\text {th }}$, and $13^{\text {th }}$ floors, and along the highpressure riser at the $14^{\text {th }}, 18^{\text {th }}$, and $21^{\text {st }}$ floors. 
The water-flow direction is from the bottom to the top, and the mass flow rate per square metre gradually drops along the water supply direction; the top floor receives the lowest flow rate, even though the top floor could be expected to have a greater heat demand than the others due to its greater exterior surface. The data shows that the flow supply per square metre to each floor is unequal; moreover, the flow is higher than the design value of 1.1 $\mathrm{kg} / \mathrm{m}^{2} \cdot \mathrm{h}$ even on the top floor.

In summary, CASE-Beijing showed that the heating system was in hydraulic unbalance, both in the DH distribution network and in the building distribution system. CASE-Beijing reflects the general hydraulic situation of Chinese heating systems. Hydraulic unbalance occurs mostly due to the lack of appropriate control devices in the heating system. Given that the whole building receives the design heat demand, any hydraulic unbalance in the building will lead to overflow condition in some rooms and underflow condition in others, leading to that some rooms cannot reach $18^{\circ} \mathrm{C}$ room temperature. This results in that the heat supply is increased until the critical users achieve $18^{\circ} \mathrm{C}$, which further aggregates the overflow condition and its inevitable consequences on the system efficiency. Consequently, the heating system is operating under large flow with small temperature differences. In addition, by the nature of the Chinese district heating system any heat supply that results in higher than standard room temperature is essentially a heat loss. Due to the constant flow principle and inherently transportation delay in the distribution system, hydraulic unbalance will in general terms then add to the overheating of the buildings and consequent open window heat regulation.

\section{Methodology}

In view of the problems mentioned above, the main purpose of this study was to clarify how the technical approach presented in this study can manage the pressure and flow in multi-storey buildings and thus achieve hydraulic balance and reduce the energy consumption. The aim of this analysis was to simulate the typical Chinese building heating systems, unlike western district heating systems, they usually operate as constant flow system throughout the heating season. The constant flow nature of the Chinese heating systems is a result from the fact that there are no automatic balancing controls applied in the systems. Due to this fact, the central hypothesis of this study rests on the philosophy that the design flow must pass through each radiator at design condition to build the hydraulic balance. Once the flows through the radiators are controlled, both excess flow and insufficient flow can be effectively avoided in all the radiators. The flow distribution in all the branches is even, and hydraulic balancing is achieved in all conditions, under both peak load and partial load conditions. To verify that the proposed approach can give the heating system hydraulic balance in an unfavourable situation, this research was carried out based on the design condition. The research object in this study was a typical multistorey building heating system, in which the heat from the DH network is supplied to the interior of the building via a heat entrance, and then distributed to a number of apartments located on different floors along the vertical riser. Each apartment has its own two-pipe heating loop.

\subsection{Control devices}

TRVs and automatic balancing valves are the two key components that are integrated in this technical approach.

TRVs consist of a thermostatic sensor and a radiator valve. An important function of radiator valve is the integrated pre-setting function, which can adjust the flow through the valve to the required value by changing the opening of the valve, namely by adjusting the pre-setting levels. 
Generally, the $k_{v}$ value is used to describe the flow capacity of the valve, and depends on the degree to which the valve is opened. When the valve is fully open, the specific $k_{v}$ obtained is called the $k_{v s}$, which is defined as the maximum flow rate that goes through the valve under a pressure drop across the valve of 1 bar (Frederiksen and Werner 2013). The actual flow, $q\left(\mathrm{~m}^{3} / \mathrm{h}\right)$, through the valve for a given pressure drop, $\Delta P$ (bar), across the valve can be calculated using Eq. (1):

$q=k_{v} \sqrt{\Delta P}$

Some specific radiator valves, e.g. a type RA-N radiator valve (Danfoss 2014) with no pre-setting, have a $k_{v s}$ of $0.53\left(\mathrm{~m}^{3} / \mathrm{h} /(\mathrm{bar})^{1 / 2}\right)$ when the valve is fully open. If a radiator valve has an integrated pre-setting function, this means the $k_{v}$ value of the valve can be adjusted in a discontinuous, level-by-level way. For instance, a type RA$\mathrm{N}$ radiator valve with a pre-setting function has pre-setting scales ranging from 1 to 7 and $\mathrm{N}$. Each scale corresponds to a maximum flow coefficient; at $\mathrm{N}$, the valve is fully open. The pre-setting of the radiator valve is done in accordance with the expected available DP across the valve and the required design flow through the valve.

A radiator valve with no pre-setting means the valve can be either fully open or fully closed, unless a thermostatic sensor is mounted on the radiator valve. Some misunderstanding exists that the installation of radiator valves that do not have an integrated pre-setting function, can ensure hydraulic balancing is obtained automatically, because the function of radiator valve is to adjust the flow through the radiator to the correct values. In fact, the radiators in an apartment generally have various heat loads, but the same size radiator valves are usually installed on all radiators. The pressure drop on the radiator can be negligible, so the same flow will go into all the radiators. This flow rate might suit one of the radiators, but it means excess flow or insufficient flow for other radiators. To achieve the hydraulic balance it is therefore important to apply radiator valves with integrated pre-setting functions. The purpose of the pre-setting function is to limit the maximum flow rate through the radiator valve in accordance to the peak demand of the radiator. Once pre-setting of the radiator valve has been performed hydraulic balance has been achieved at design conditions.

Based on Eq. (1), it is easy to see that the flow through the radiator valves will be influenced when the pressure drop across the valves changes. Since excess of differential pressure on the valves could cause noise and the increased flow rate might carry impurities so that the risk of clogging is high, the pressure drop across the radiator valve needs to be controlled to ensure good adjustment effects. Good regulation of the radiator valve requires a constant DP across the valve. This constant DP can be created and maintained by using a DP controller. The constant DP protects downstream control valves from excessive pressure and offsets the effects of pressure variations caused by the movement of control valves in other branches. For radiator valves, the maximum pressure drop should not exceed 30-35 kPa, and most radiator applications use a DP range of 5-25 $\mathrm{kPa}$ (British Standards Institution 2004). With the installation of a DP controller, all of the controlled loops also become pressure-independent zones. This eliminates any problems caused by high or excessive system pressures, including noise from the valves and poor control of room temperatures.

The DP controller and the radiator valve are the two key control devices used in this study. With these two control devices, terminal units (radiators) can achieve rational flow allocation, so that the entire building heating system is kept in hydraulic balance under all load conditions. 


\subsection{The integrated model}

An integrated model was used to investigate the hydraulic performance and the heat performance of the building heating system when the pressure and flow are either controlled or not controlled. Figure 4 shows a schematic layout of the heating system. The model consisted of two parts: a building model and a hydraulic model. The building model was developed using the commercial software Indoor Climate and Energy (IDA-ICE) 4.6.2 (EQUA 2015), from which the building heating system was derived. Based on the heating system, the physical properties of the hydraulic model were known, and we developed a mathematical hydraulic model based on Kirchhoff's laws.

\subsubsection{Building model}

The simplified building model consisted of three floors of a multi-storey building in Beijing. Each floor had an apartment with three rooms. All the rooms were identical, with a heating area of $37.5 \mathrm{~m}^{2}$ and a height of $3.0 \mathrm{~m}$. The building was to meet the $3^{\text {rd }}$ step of the energy efficiency standards for Beijing. This implies that the design heat load per room was $1200 \mathrm{~W}$ under design conditions. Moreover, the construction envelope properties and the thermal characteristics for the building model, including external/internal walls, internal floors, roof and ground, windows and doors, window glazing, etc., as well as thermal bridges and the window-to-wall ratio, were all as specified in China's design standard (Ministry of Housing and Urban-Rural Development of China 2010). The building was modelled as a multi-zone model, which means that each room was modelled as an individual zone. Because the model was used to investigate the heat performance of a multi-storey building under design conditions, synthetic weather data were used: the outdoor ambient temperature was constant and kept at $-9{ }^{\circ} \mathrm{C}$. Furthermore, to simulate this most unfavourable situation, the influence of solar radiation and mechanical ventilation on indoor temperatures was disregarded.

For the SH installation, the design was carried out in accordance with (Lu 2008). The design heat load for all rooms was $1200 \mathrm{~W}$. The design temperatures of the radiator heating system were $75 / 50 / 18{ }^{\circ} \mathrm{C}$ (supply/return/indoor temperatures). Firstly, the pipeline layouts of the building heating system were arranged. To keep things simple, the horizontal pipe length between the riser and the radiator, and between one radiator and the next were all simply considered to be 10 metres. The riser height for each floor was $3 \mathrm{~m}$. Secondly, the design flow rates of the radiators were determined in accordance with the peak heat load and design temperatures. The radiators were KORADO “Type 22" panel steel radiators (KORADO 2014). Thirdly, a hydraulic calculation of the building heating was made. The dimensions of pipes were defined in accordance with [Jing et al. 2014]. On this basis, the dimensions of all indoor heating pipes were DN15, and the riser pipe sizes on the $1^{\text {st }}, 2^{\text {nd }}$, and $3^{\text {rd }}$ floors were DN25, DN20, and DN15, respectively. Accordingly, the DPs of these three apartment heating loops were calculated and all were less than $5 \mathrm{kPa}$ under the design flow rates. RA-Ntype radiator valves with a dimension of DN15 were therefore used (Danfoss 2014). As DP controllers, an ASVPV (Danfoss 2014) was applied in the return pipe, and its associated partner shut-off valve ASV-M (Danfoss 2014) was applied in the supply pipe. The ASV-PV and ASV-M were linked to each other with a capillary tube; together they are known as automatic balancing valves. They were located in the staircase hall, which is also where the heat entry point of the apartment heating loop was located. 


\subsubsection{Hydraulic model}

\subsubsection{Flow coefficient}

According to basic fluid mechanics, the pressure drop for a given length of circular pipe is caused by friction along the length of the pipe, and by local resistance from pipe fittings, valves, forks, bends, etc. Furthermore, in the light of the Darcy-Weisbach equation, the relationship between flow and pressure drop in a given pipe $i$ can be expressed by Eq. (2):

$\Delta P_{i}=\left(\frac{\lambda_{i}}{d_{i}} l_{i}+\sum_{n=0}^{n} \zeta_{n}\right) \frac{1}{900^{2} \pi^{2} d_{i}{ }^{4} 20 \rho_{w}^{2}} q_{v, i}^{2}$

where $\Delta P_{i}$ (bar) is the pressure drop in pipe $i ; \lambda_{i}$ is the friction factor of pipe $i ; d_{i}(\mathrm{~mm})$ is the diameter of pipe $i$; $l_{i}(\mathrm{~m})$ is the length of pipe $i ; \zeta_{n}$ is the number $n$ of local resistance coefficients in pipe $i ; \rho_{w}\left(\mathrm{~kg} / \mathrm{m}^{3}\right)$ is the water density; and $q_{v, i}\left(\mathrm{~m}^{3} / \mathrm{h}\right)$ is the volume flow through pipe $i$.

Changes in the throttle section of a control valve change its $k_{v}$ value. Pipes without control devices have a constant $k_{v}$ value. It can therefore be said that changing the $k_{v}$ value of certain pipes, which can be done by presetting the radiator valves, changes the flow distribution in the heating system, and thus flow control can be achieved. On the other hand, for any given $k_{v}$ value, the DP across the valve also influences the flow through the valve. A constant DP across the valve is therefore required to ensure good regulation of the radiator valve.

Once the heating system was designed and the piping configuration was determined, so that the design flow, the pipe dimensions, pipe lengths, and local resistance coefficients were known, the pressure drop for each pipe could be calculated using Eq. (2). Subsequently, the $k_{v}$ values of the pipes were calculated in accordance with Eq. (1). When the radiator valve was pre-set or fully open, the $k_{v}$ values of the radiator branch pipes were changed correspondingly.

\subsubsection{Mathematical model for a simplified case}

Water flow in the heating network follows Kirchhoff's laws. According to the First Law of Kirchhoff, at any node in a hydraulic network, the sum of the water flow into that node is equal to the sum of the water flow out of that node, which can be expressed as Eq. (3):

$\sum_{n=1}^{m} q_{v, n}=0$

where $q_{v, n}\left(\mathrm{~m}^{3} / \mathrm{h}\right)$ is the volume flow of branch $n . q_{v, n}$ has a positive or negative value depending on whether the flow is into or out of the node.

According to the Second Law of Kirchhoff, the directed sum of the DP around any closed network is zero. This can be expressed as Eq. (4):

$\sum_{n=1}^{m}\left[\left(\frac{q_{v, n}^{2}}{k_{v, n}^{2}}\right)-\Delta P_{n}\right]=0$ 
For a system of pipelines connected in series, the pressure drop for the entire loop, $\Delta P_{S}$, is the sum of the pressure drop in each pipeline, $\Delta P_{n}$. This can be expressed as Eq. (5). Moreover, based on Eq. (1), the equation can also be expressed by $k_{v, S}$ for the entire loop, and by $k_{v, n}$ for each individual pipeline, as in Eq. (6).

$\begin{aligned} \Delta P_{S} & =\sum_{n=1}^{m} \Delta P_{n} \\ \frac{1}{k_{v, S}^{2}} & =\sum_{n=1}^{m} \frac{1}{k_{v, n}^{2}}\end{aligned}$

For a system of pipelines connected in parallel, the volume flow for the entire loop, $q_{v, S}$, is equal to the sum of the volume flow through each branch pipe, $q_{v, n}$, as expressed by Eq. (7). This can also be expressed in $k_{v}$ values, as in Eq. (8).

$q_{v, S}=\sum_{n=1}^{m} q_{v, n}$
$k_{v, S}=\sum_{n=1}^{m} k_{v, n}$

\subsubsection{Mathematical model}

Based on the schematic layout of the integrated model (Figure 4), both the whole building heating system (with three apartments) and each apartment heating system (with three radiators) can be considered as a simple heating system with three loops (Figure 5).

According to Kirchhoff's laws, and the series connection and parallel connection of the pipelines, the set of equations for this mathematic model can be written as Eqs. (9) - (15):

$\frac{q_{v, R 1}}{q_{v, R 2}+q_{v, R 3}}=\frac{k_{v, R 1}}{k_{v-b c d e f g}}$ 
$\frac{q_{v, R 2}}{q_{v, R 3}}=\frac{k_{v, R 2}}{k_{v-c d e f}}$

When the available DP for this system $\Delta P_{S}$ is determined, and the $k_{v, 1 s}, k_{v, 1 r}, k_{v, R 1}, k_{v, 2 s}, k_{v, 2 r}, k_{v, R 2}, k_{v, 3 s}$, $k_{v, 3 r}$, and $k_{v, R 3}$ values for each pipe are known, the volume flow, $q_{v, R 1}, q_{v, R 2}$, and $q_{v, R 3}$, for each branch pipe can be calculated based on Eqs. (9) - (15). From the mathematical model, the flow distribution between the radiators and the apartment heating loops is known, and the hydraulic performance of the heating system is clarified. The volume flows obtained from this mathematical model were used as inputs into the IDA-ICE building model; subsequently, the room temperatures, i.e. the temperatures of each zone, could be simulated, and the heat performance of the model determined.

\subsection{Scenarios}

To test the effects of this integrated approach, four scenarios were developed. The reference was the distributed design flow with no pressure or flow control measures. In the four scenarios, the DP controllers and radiator valves had different applications (Table 1). Because the calculated pressure drop in the three floor loops is the same and less than $5 \mathrm{kPa}$ under the design conditions, when the DP controller was at the apartment level, the available DP for each loop was set to $5 \mathrm{kPa}$. When the DP controller was at the riser level, the available DP ensured that the $3^{\text {rd }}$ floor apartment loop obtained $5 \mathrm{kPa}$. The heat consumption, pump electricity consumption, indoor temperature, and return temperature in the building heating system were compared for the four scenarios. The units for heat consumption and pump electricity consumption were unified as $\mathrm{kWh}$ and temperatures are presented in ${ }^{\circ} \mathrm{C}$ to facilitate comparison of the scenarios and determine the optimum approach.

Table 1. The reference and the four scenarios

\begin{tabular}{ccccccc}
\hline Control conditions & $\begin{array}{c}\text { No DP controllers, } \\
\text { just pipes }\end{array}$ & \multicolumn{2}{c}{ Apply DP controllers } & \multicolumn{2}{c}{ Ro radiator valves, } & \multicolumn{2}{c}{ Apply radiator valve } \\
Riser level & $\begin{array}{c}\text { Apartment } \\
\text { level }\end{array}$ & just pipes & No pre-setting & With pre-setting \\
\hline Reference & $\sqrt{n}$ & - & - & $\sqrt{ }$ & - & - \\
Scenario 1 & - & $\sqrt{ }$ & - & - & $\sqrt{ }$ & - \\
Scenario 2 & - & - & $\sqrt{ }$ & - & - & - \\
Scenario 3 & - & - & - & - & - & $\sqrt{ }$ \\
Scenario 4 & - & - & $\sqrt{ }$ & - & - & $\sqrt{ }$ \\
\hline
\end{tabular}

\section{Results and discussion}

\subsection{Validation of building model}

The building model was developed in accordance with "Industry standard JGJ 26-2010" (Ministry of Housing and Urban-Rural Development of China 2010), the standard according to which the buildings in the network were built. The thermal characteristics of the building that was modelled, which is representative of all the buildings in the network, are an indoor air temperature of $18{ }^{\circ} \mathrm{C}$ and a heat demand of $32 \mathrm{~W} / \mathrm{m}^{2}$ at an outdoor design temperature of $-9^{\circ} \mathrm{C}$. The radiator heating system is designed to be able to maintain the room temperature around $18{ }^{\circ} \mathrm{C}$, given a $75^{\circ} \mathrm{C}$ supply temperature, and to cool the return to $50{ }^{\circ} \mathrm{C}$.

With the outdoor temperature at $-9{ }^{\circ} \mathrm{C}$ and the supply temperature of the heating system at $75{ }^{\circ} \mathrm{C}$, we ran the model in IDA-ICE 4.6.2; the simulation results showed the mean air temperature for all zones was around $19{ }^{\circ} \mathrm{C}$ (Figure 6). The specific room temperatures for the zones are listed in Table 2. The average indoor temperature 
was $18.8{ }^{\circ} \mathrm{C}$, and the deviation from the minimum design indoor temperature of $18{ }^{\circ} \mathrm{C}$ was less than $1{ }^{\circ} \mathrm{C}$, which is reasonable and acceptable. Moreover, the room unit heat demand for all zones was $31.5-32 \mathrm{~W} / \mathrm{m}^{2}$, and the return temperature of the heating system was $50{ }^{\circ} \mathrm{C}$. Therefore, the heat demand of the building model and the heat supplied by the radiator heating system were consistent under design conditions. The building model with the derived heating system was developed in IDA-ICE and was used for the investigation.

Table 2. The design flows and indoor temperatures for the building model

\begin{tabular}{lccccccccccc}
\hline Items & Radiator & Radiator & Radiator & Radiator & Radiator & Radiator & Radiator & Radiator & Radiator & Total flow \\
& 101 & 102 & 103 & 201 & 202 & 203 & 301 & 302 & 303 & $(\mathrm{~kg} / \mathrm{h})$ \\
\hline Design flow $(\mathrm{kg} / \mathrm{h})$ & 41.3 & 41.3 & 41.3 & 41.3 & 41.3 & 41.3 & 41.3 & 41.3 & 41.3 & \\
Room temperature $\left({ }^{\circ} \mathrm{C}\right)$ & 18.7 & 18.8 & 18.7 & 18.8 & 18.9 & 18.9 & 18.9 & 19.0 & 19.0 & 371.3
\end{tabular}

\subsection{Scenarios}

\subsubsection{Flow distributions and room temperatures}

Using the hydraulic model and the building model, we investigated the flow requirements and heat delivery when the pressure and flow control measures were adopted or not, and the results are listed in Table 3. First, it is clear that with no flow or pressure control (i.e., the reference case), there was a hydraulic unbalance in the entire heating system, as well between the radiators for each apartment loop. In order for the critical Radiator 303, which is the last radiator in the $3^{\text {rd }}$ floor apartment loop, to receive sufficient flow to achieve the standard room temperature, the excess flow of the whole heating system was $321 \%$. Moreover, the first radiators for each floor, namely Radiator 101, Radiator 201, Radiator 301, encountered severe excess flows of $870 \%, 778 \%$, and $686 \%$, respectively. Correspondingly, the room temperatures were well beyond the design level, probably forcing the opening of windows and ultimately wasting energy. This result is also very clear.

Table 3. Comparison of the simulation results for the reference and the four scenarios

\begin{tabular}{|c|c|c|c|c|c|c|c|c|c|c|c|c|}
\hline $\begin{array}{l}\text { Control } \\
\text { conditions }\end{array}$ & Items & $\begin{array}{c}\text { Radiator } \\
101\end{array}$ & $\begin{array}{l}\text { Radiator } \\
102\end{array}$ & $\begin{array}{l}\text { Radiator } \\
103\end{array}$ & $\begin{array}{c}\text { Radiator } \\
201\end{array}$ & $\begin{array}{l}\text { Radiator } \\
202\end{array}$ & $\begin{array}{l}\text { Radiator } \\
203\end{array}$ & $\begin{array}{l}\text { Radiator } \\
301\end{array}$ & $\begin{array}{l}\text { Radiator } \\
302\end{array}$ & $\begin{array}{l}\text { Radiator } \\
303\end{array}$ & $\begin{array}{l}\text { Total } \\
\text { flow } \\
(\mathrm{kg} / \mathrm{h})\end{array}$ & $\begin{array}{l}\text { Average } \\
\text { excess } \\
\text { flow }(\%)\end{array}$ \\
\hline \multirow[t]{4}{*}{ Reference } & $\mathrm{kv}$ value & 2.28 & 2.28 & 2.28 & 2.28 & 2.28 & 2.28 & 2.28 & 2.28 & 2.28 & \multirow{4}{*}{1565.1} & \multirow{4}{*}{$321 \%$} \\
\hline & Flow (kg/h) & 400.5 & 125.1 & 50.7 & 362.6 & 113.2 & 45.9 & 324.6 & 101.4 & 41.1 & & \\
\hline & $\begin{array}{l}\text { Room } \\
\text { temperature }\left({ }^{\circ} \mathrm{C}\right)\end{array}$ & 27.4 & 23.4 & 20.1 & 27.2 & 23.2 & 19.5 & 27.0 & 23.0 & 18.8 & & \\
\hline & Excess flow (\%) & $870 \%$ & $203 \%$ & $23 \%$ & $778 \%$ & $174 \%$ & $11 \%$ & $686 \%$ & $146 \%$ & $0 \%$ & & \\
\hline \multirow[t]{4}{*}{ Scenario 1} & kv value & 0.52 & 0.52 & 0.52 & 0.52 & 0.52 & 0.52 & 0.52 & 0.52 & 0.52 & \multirow{4}{*}{535.2} & \multirow{4}{*}{$44 \%$} \\
\hline & Flow (kg/h) & 80.6 & 59.0 & 52.4 & 74.9 & 54.8 & 48.7 & 69.2 & 50.6 & 45.0 & & \\
\hline & $\begin{array}{l}\text { Room } \\
\text { temperature }\left({ }^{\circ} \mathrm{C}\right)\end{array}$ & 21.2 & 20.5 & 20.0 & 21.1 & 20.4 & 19.9 & 21.1 & 20.3 & 19.8 & & \\
\hline & Excess flow (\%) & $95 \%$ & $43 \%$ & $27 \%$ & $81 \%$ & $33 \%$ & $18 \%$ & $68 \%$ & $23 \%$ & $9 \%$ & & \\
\hline \multirow[t]{4}{*}{ Scenario 2} & $\mathrm{kv}$ value & 0.52 & 0.52 & 0.52 & 0.52 & 0.52 & 0.52 & 0.52 & 0.52 & 0.52 & \multirow{2}{*}{494.4} & \multirow{2}{*}{$33 \%$} \\
\hline & Flow (kg/h) & 69.2 & 50.6 & 45 & 69.2 & 50.6 & 45 & 69.2 & 50.6 & 45 & & \\
\hline & $\begin{array}{l}\text { Room } \\
\text { temperature }\left({ }^{\circ} \mathrm{C}\right)\end{array}$ & 20.8 & 20.0 & 19.4 & 20.9 & 20.1 & 19.6 & 20.9 & 20.2 & 19.7 & & \\
\hline & Excess flow (\%) & $68 \%$ & $23 \%$ & $9 \%$ & $68 \%$ & $23 \%$ & $9 \%$ & $68 \%$ & $23 \%$ & $9 \%$ & & \\
\hline \multirow{2}{*}{ Scenario 3} & $\mathrm{kv}$ value & 0.21 & 0.27 & 0.27 & 0.27 & 0.27 & 0.31 & 0.27 & 0.31 & 0.31 & \multirow{2}{*}{409.5} & \multirow{2}{*}{$10.2 \%$} \\
\hline & Flow (kg/h) & 41.8 & 48.0 & 46.3 & 48.8 & 43.0 & 47.2 & 45.6 & 45.4 & 43.4 & & \\
\hline
\end{tabular}




\begin{tabular}{|c|c|c|c|c|c|c|c|c|c|c|c|}
\hline $\begin{array}{l}\text { Room } \\
\text { temperature }\left({ }^{\circ} \mathrm{C}\right)\end{array}$ & 19 & 19.4 & 19.3 & 19.4 & 19.3 & 19.5 & 19.4 & 19.5 & 19.4 & \multirow{6}{*}{403.2} & \multirow{6}{*}{$8.5 \%$} \\
\hline Excess flow $(\%)$ & $1 \%$ & $16 \%$ & $12 \%$ & $18 \%$ & $4 \%$ & $14 \%$ & $10 \%$ & $10 \%$ & $5 \%$ & & \\
\hline kv value & 0.27 & 0.31 & 0.31 & 0.27 & 0.31 & 0.31 & 0.27 & 0.31 & 0.31 & & \\
\hline Flow (kg/h) & 45.6 & 45.4 & 43.4 & 45.6 & 45.4 & 43.4 & 45.6 & 45.4 & 43.4 & & \\
\hline $\begin{array}{l}\text { Room } \\
\text { temperature }\left({ }^{\circ} \mathrm{C}\right)\end{array}$ & 19.2 & 19.3 & 19.1 & 19.3 & 19.4 & 19.2 & 19.4 & 19.5 & 19.4 & & \\
\hline Excess flow (\%) & $10 \%$ & $10 \%$ & $5 \%$ & $10 \%$ & $10 \%$ & $5 \%$ & $10 \%$ & $10 \%$ & $5 \%$ & & \\
\hline
\end{tabular}

On the other hand, when pressure and control measures were employed in the heating system (in the four scenarios), the excess flow was much more controlled, and the deviation in indoor temperature between the simulated results and the design values became smaller as well. Looking at the four scenarios, when radiator valves with no pre-setting were used with DP controllers at the riser level or the apartment level (Scenarios 1 and 2 , respectively), the average excess flows of the heating system were more than $15 \%$, there was hydraulic unbalance in the heating system, and the room temperatures were uneven and deviated from the design values. When radiator valves with pre-setting were used and were pre-set in combination with the DP controllers at the riser level or the apartment level (Scenarios 3 and 4, respectively), the average excess flows of the heating system were controlled within $15 \%$, the heating system was in hydraulic balance, and the room temperatures were even and close to the design values, averaging $18.8^{\circ} \mathrm{C}$. In terms of flow distribution and room temperatures, Scenario 4 had a slightly smaller average excess flow than Scenario 3. The deviation from the design flow occurred because the radiator valve with pre-setting is a discontinuous controller, so it is not always exact. The average room temperature for Scenario $4\left(19.3{ }^{\circ} \mathrm{C}\right)$ is also just slightly closer to the design average indoor temperature of $18.8^{\circ} \mathrm{C}$ than Scenario $3\left(19.4^{\circ} \mathrm{C}\right)$.

The simulation results show that the lack of appropriate flow and pressure management inevitably causes hydraulic unbalance. To achieve the standard room temperature for the critical end users, DH suppliers increase the flow, creating more hydraulic unbalance and excess flow in the system. This means hydraulic unbalance is related to overheated rooms, unsatisfactory indoor thermal comfort, windows being opened, and much more pump electricity consumption than under conditions of hydraulic balance. All this implies higher energy consumption and lower operating efficiency, all of which threatens China's energy security and air pollution abatement policy.

\subsubsection{Energy consumption and return temperatures}

Figure 7 compares the reference and the four scenarios on heat consumption, pump power consumption, and return temperature. The simulation results show that Scenario 4 has the least heat consumption at $83.8 \%$ of the reference, the least pump electricity consumption at $26.3 \%$ of the reference, and the lowest return temperature at $52.1^{\circ} \mathrm{C}$. This means that having DP controllers at the apartment level, combined with pre-set radiator valves (Scenario 4) achieved hydraulic balance in the heating system, brought room temperatures close to the design level, and reduced the return temperature of the heating system. Furthermore, this solution dramatically reduced the electricity consumption of the pumps by nearly $74 \%$, and gave a $16 \%$ heat consumption saving.

As mentioned before, the seasonal heat consumption per square metre of the buildings in CASE-Beijing is 0.15 $\mathrm{GJ} / \mathrm{m}^{2}$, so a $16 \%$ heat consumption saving implies a heat reduction of $0.024 \mathrm{GJ} / \mathrm{m}^{2}$ during the heating season. Furthermore, coal is the dominant DH fuel in China (You and Xu 2010). Statistics show that $91 \%$ of the total 
energy supply to DH systems came from coal in 2008 (Baeumler et al. 2012). Therefore, any reduction in consumption will lead to reduced emissions. Burning one ton Chinese standard coal $(29.3 \mathrm{GJ} / \mathrm{tce})$ releases about $2600 \mathrm{~kg} \mathrm{CO}_{2}, 24 \mathrm{~kg} \mathrm{SO}_{2}, 7 \mathrm{~kg} \mathrm{NO}_{\mathrm{x}}$ (Price et al. 2011). Consequently, a seasonal heat consumption reduction of $0.024 \mathrm{GJ} / \mathrm{m}^{2}$ implies a reduction of $2.1 \mathrm{~kg} / \mathrm{m}^{2} \mathrm{CO}_{2}, 0.02 \mathrm{~kg} / \mathrm{m}^{2} \mathrm{SO}_{2}$, and $0.01 \mathrm{~kg} / \mathrm{m}^{2} \mathrm{NOx}$ for CASE-Beijing. If the proposed controls are applied in Chinese DH systems, appropriate energy consumption savings would be achieved which would consequently have positive environmental impacts.

These results show that a well-balanced building hydronic circuit can be achieved under design conditions by applying the technical approach proposed. This approach ensures the flow through each radiator never exceeds the required maximum value, which limits the excess flow for all radiators under any conditions. At the present time, most Chinese building heating systems are operated as constant flow systems: the flow rates are fixed so the hydraulic situation remains balanced under various load conditions; and the varying heating loads are met by varying the supply temperatures. On the other hand, these are good preconditions for mounting thermostatic sensors on the radiator valves. As the thermostats are activated, the flows into the radiators will be limited and even completely closed depending on the desired room temperatures. That will transform the heating system from constant flow to variable flow and allow the return temperature to be further decreased. Reducing the return temperature as low as possible will allow subsequent improvements in heat source efficiency. Furthermore, once the thermostatic sensor has been installed further energy savings can be achieved as it will prevent the inherit oversupply experienced in constant flow systems when the outdoor temperatures are higher than the design value. This approach not only makes the necessary technical preparation, but will also create hydraulic balance when the application of TRVs becomes more widely used in Chinese heating systems in the coming years.

Nevertheless, it is worth noting that the differences between Scenario 3 and Scenario 4 are limited in terms of both energy consumption and indoor temperatures. Therefore, it is wise to find a balance between the cost of initial product investment and the later operating costs of the heating system. However, applying DP controllers at the apartment level provides some additional benefits for the system:

Some risks can effectively be avoided, such as man-made changes or misuse of the initial pre-setting of the radiator valves, which might be fully opened and cause hydraulic unbalance, affecting other loops and perhaps the whole riser heating system, as well as causing noise and probably blockage issues.

Furthermore, applying DP controllers at the apartment level can make the commissioning work easy and rapid. Multi-storey buildings usually have the same layout on every floor, so the rooms located on different floors but in the same vertical position usually have the same heating area and heat demand, and radiators located on different floors but in the same vertical position could have the same pre-setting value. In contrast, applying DP controllers at the riser level is more complex because the pressure drop for apartment loops on different floors is different, so that the pre-setting work in high-rise buildings might become relatively complicated due to the building's height.

\section{Conclusions}

An integrated model for the simulation of the heat performance and hydraulic situation of a two-pipe multistorey building heating system in China has been developed, validated, and applied to analyse pressure and flow conditions. The simulation results indicate that the technical approach of combining DP controllers with radiator valves will significantly improve the hydraulic conditions, as compared with no pressure or flow control. 
Without pressure and flow controls, increases in the flow rate to ensure sufficient room temperatures to distal or critical rooms result in considerable hydraulic unbalance, large flow rates, and high pump electricity consumption. In contrast, combining DP controllers at the apartment level with pre-set radiator valves achieves a fair flow distribution, room temperatures that are close to design values, $16 \%$ heat savings, $74 \%$ pump electricity savings, and a difference between the supply and return temperatures that is close to the design value. These results verify that the hypothesis presented in the paper is valid: hydraulic balancing optimizes the flow distribution in the building's heating system so that it provides the intended indoor room temperature at optimal energy efficiency and minimal operating cost.

For the appropriate application, there are small differences in heat performance and energy consumption between applying the DP controllers at the apartment level or at the riser level in combination with pre-setting radiator valves. Both control solutions achieve hydraulic balance in the heating system. In terms of financial factors, it is important to take into account both the initial investment cost and the potential increase in operating costs in the event of misuse of radiator valves with DP controllers applied at the riser level, as well the increased complexity of commissioning this solution.

The technical approach proposed here fits the current constant flow principle in heating systems, but also makes technical preparations for the future when TRVs become widely used and heating systems are transformed from constant flow to variable flow.

The approach proposed could help decision-makers and stakeholders to plan new or renovated DH projects to be more energy-efficient and cost-effective. It would make a considerable contribution to energy supply security and air pollution abatement for Chinese society by giving smart control to heating systems.

\section{Acknowledgements}

The research reported here was carried out with financial support from the Danish Agency for Science, Technology and Innovation (DASTI), and from Danfoss A/S through the Industrial PhD Programme for China. This financial support is gratefully acknowledged.

\section{References}

Baeumler A, Ijjasz-vasquez E, Mehndiratta S (2012). Sustainable Low-Carbon City Development in China. World Bank, doi:10.1596/978-0-8213-8987-4

British Standards Institution (2004). BS EN 215:2004 Thermostatic radiator valves - requirements and test methods. British Standards Institution.

Building Energy Research Center of Tsinghua University (2011). Annual Report on China Building Energy Efficiency in 2011. China, Beijing: China Architecture \& Building Press (In Chinese).

Cao B, Zhu Y, Li M, Ouyang Q (2014). Individual and district heating: A comparison of residential heating modes with an analysis of adaptive thermal comfort. Energy Build., 78: 17-24.

Chen X, Wang L, Tong L, Sun S, Yue X, Yin S, Zheng L (2013). Energy saving and emission reduction of China's urban district heating. Energy Policy, 55: 677-682. 
Danfoss (2014). RA-N Valves with Pre-Setting. Available at: http://products.danfoss.com/productrange/list/heatingsolutions/radiator-thermostats/radiator-valves/presetting-valves/. Accessed 21 Jan.2015.

Danfoss (2014). ASV Automatic Balancing Valves. Available at: http://products.danfoss.com/productrange/heatingsolutions/balancing-control-valves/automatic-balancingvalves/asv-automatic-balancing-valves/. Accessed 21 Jan 2015.

EQUA (2015). IDA-ICE 4.2.6. Available at: http://www.equa.se/index.php/en/ida-ice.

EURO HEAT \& POWER (2013). Eruoheat \& power - Statistics. Available at: http://www.euroheat.org/Statistics-69.aspx. Accessed 26 October 2015.

Fang H, Xia J, Lu A, Jiang Y (2013a). An operation strategy for using a ground heat exchanger system for industrial waste heat storage and extraction. Build. Simul., 7: 197-204.

Fang H, Xia J, Zhu K, Su Y, Jiang Y (2013b). Industrial waste heat utilization for low temperature district heating. Energy Policy, 62: 236-246.

Frederiksen S, Werner S (2013). District Heating and Cooling. Sweden, Lund: Studentlitteratur AB.

Hong L, Zhou N, Fridley D, Raczkowski C (2013). Assessment of China's renewable energy contribution during the 12th Five Year Plan. Energy Policy, 62: 1533-1543.

Jiang X, Jing Z, Li Y, Wu Q, Tang W (2014). Modelling and operation optimization of an integrated energy based direct district water-heating system. Energy, 64: 375-388.

Jie P, Tian Z, Yuan S, Zhu N (2012). Modeling the dynamic characteristics of a district heating network. Energy, 39: $126-134$.

Jie P, Zhu N, Li D (2015). Operation optimization of existing district heating systems. Appl. Therm. Eng., 78: $278-288$.

Jing Z, Jiang X, Wu Q, Tang W, Hua B (2014). Modelling and optimal operation of a small-scale integrated energy based district heating and cooling system. Energy, 73: 399-415.

KORADO (2014). RADIK KLASIK - Steel Panel Radiator. Available at: http://www.korado.com/en/products/radiators-radik/review-of-models/radik-klasik/index.shtml\#tu. Accessed 15 Jan 2015).

Li J, Colombier M, Giraud P (2009). Decision on optimal building energy efficiency standard in China-The case for Tianjin. Energy Policy, 37: 2546-2559.

Lin B, Liu H (2015). China's building energy efficiency and urbanization. Energy Build, 86: 356-365.

Liu L, Fu L, Jiang Y (2015). An on-off regulation method by predicting the valve on-time ratio in district heating system. Build. Simul., 8: 665-672.

Liu L, Fu L, Jiang Y, Guo S (2011). Major issues and solutions in the heat-metering reform in China. Renew. Sustain. Energy Rev., 15: 673-680. 
Lu Y (2008). Practical Handbook of heating and air conditioning design. China, Beijing: China Building Industry Press (In Chinese).

Lund H, Möller B, Mathiesen B, Dyrelund A (2010). The role of district heating in future renewable energy systems. Energy, 35: 1381-1390.

Lund H, Werner S, Wiltshire R, Svendsen S, Thorsen J, Hvelplund F, Mathiesen B (2014). $4^{\text {th }}$ Generation District Heating (4GDH): Integrating smart thermal grids into future sustainable energy systems. Energy, 68: $1-11$.

Ma Z, Wang S (2009). Energy efficient control of variable speed pumps in complex building central airconditioning systems. Energy Build., 41: 197-205.

Ministry of Housing and Urban-Rural Development of China (2010). Industry standard JGJ 26-2010: Design standard for energy efficiency of residential buildings in severe cold and cold zones. China, Beijing: China Architecture \& Building Press (In Chinese).

Price L, Levine M, Zhou N, Fridley D, Aden N, Lu H, McNeil M, Zheng N, Qin Y, Yowargana P (2011). Assessment of China's energy-saving and emission-reduction accomplishments and opportunities during the 11th Five Year Plan. Energy Policy, 39: 2165-2178.

Sun F, Fu L, Zhang S, Sun J (2012). New waste heat district heating system with combined heat and power based on absorption heat exchange cycle in China. Appl. Therm. Eng., 37:136-144.

Wang C, Yan D, Jiang Y (2011). A novel approach for building occupancy simulation. Build. Simul., 4: 149-167.

Wang H, Jiao W, Lahdelma R, Zou P (2011). Techno-economic analysis of a coal-fired CHP based combined heating system with gas-fired boilers for peak load compensation. Energy Policy, 39: 7950-7962.

Xia J, Zhu K, Jiang Y (2016). Method for integrating low-grade industrial waste heat into district heating network. Build. Simul., 9: 153-163.

Xu B, Fu L, Di H (2009). Field investigation on consumer behavior and hydraulic performance of a district heating system in Tianjin, China. Build. Environ., 44: 249-259.

Xu B, Fu L, Di H (2008). Dynamic simulation of space heating systems with radiators controlled by TRVs in buildings. Energy Build., 40: 1755-1764.

Xu P, Xu T, Shen P (2013). Energy and behavioral impacts of integrative retrofits for residential buildings: What is at stake for building energy policy reforms in northern China? Energy Policy, 52: 667-676.

Xu X, You S, Zheng X, Li H (2014). A survey of district heating systems in the heating regions of northern China. Energy, 77: 909-925.

Yan A, Zhao J, An Q, Zhao Y. Li H, Huang Y (2013). Hydraulic performance of a new district heating systems with distributed variable speed pumps. Appl. Energy, 112: 876-885.

Yan D, Zhe T, Yong W, Neng Z (2011a). Achievements and suggestions of heat metering and energy efficiency retrofit for existing residential buildings in northern heating regions of China. Energy Policy, 39: 46754682. 
Yang X, Li H, Svendsen S (2016). Modelling and multi-scenario analysis for electric heat tracing system combined with low temperature district heating for domestic hot water supply. Build. Simul., 9:141-151.

You C, Xu X (2010). Coal combustion and its pollution control in China. Energy, 35: 4467-4472.

Zhang J, Ge B, Xu H (2013). An equivalent marginal cost-pricing model for the district heating market. Energy Policy, 63: 1224-1232.

Zhang L, Gudmundsson O, Li H (2015). Comparison of district heating systems used in China and Denmark. Int. J. Sustain. Green Energy, 4: 102-116.

Zhang L, Gudmundsson O, Thorsen J, Li H, Li X, Svendsen, S (2016). Method for reducing excess heat supply experienced in typical Chinese district heating systems by achieving hydraulic balance and improving indoor air temperature control at the building level. Energy, 107: 431-442.

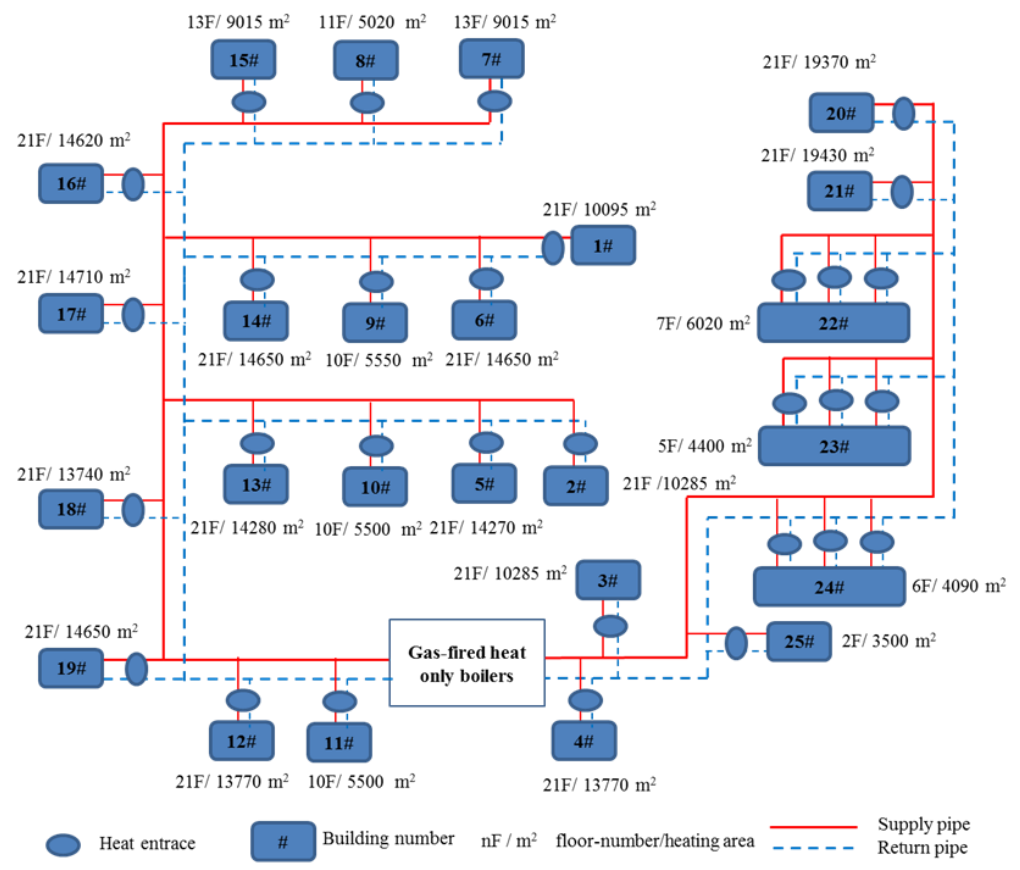

Figure 1. Heating system layout of CASE-Beijing 


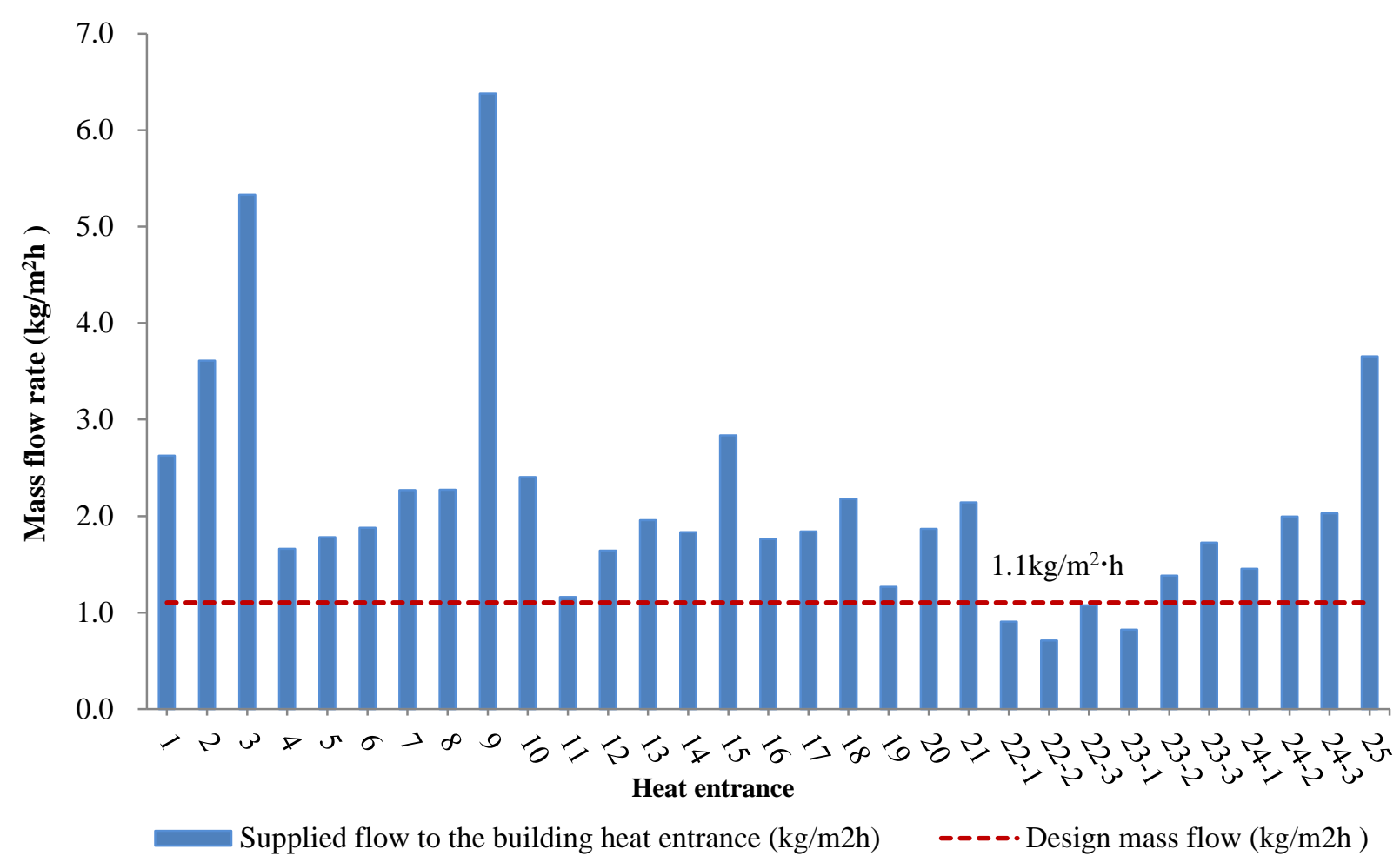

Figure 2. Mass flow of the 31 heat entrances of CASE-Beijing
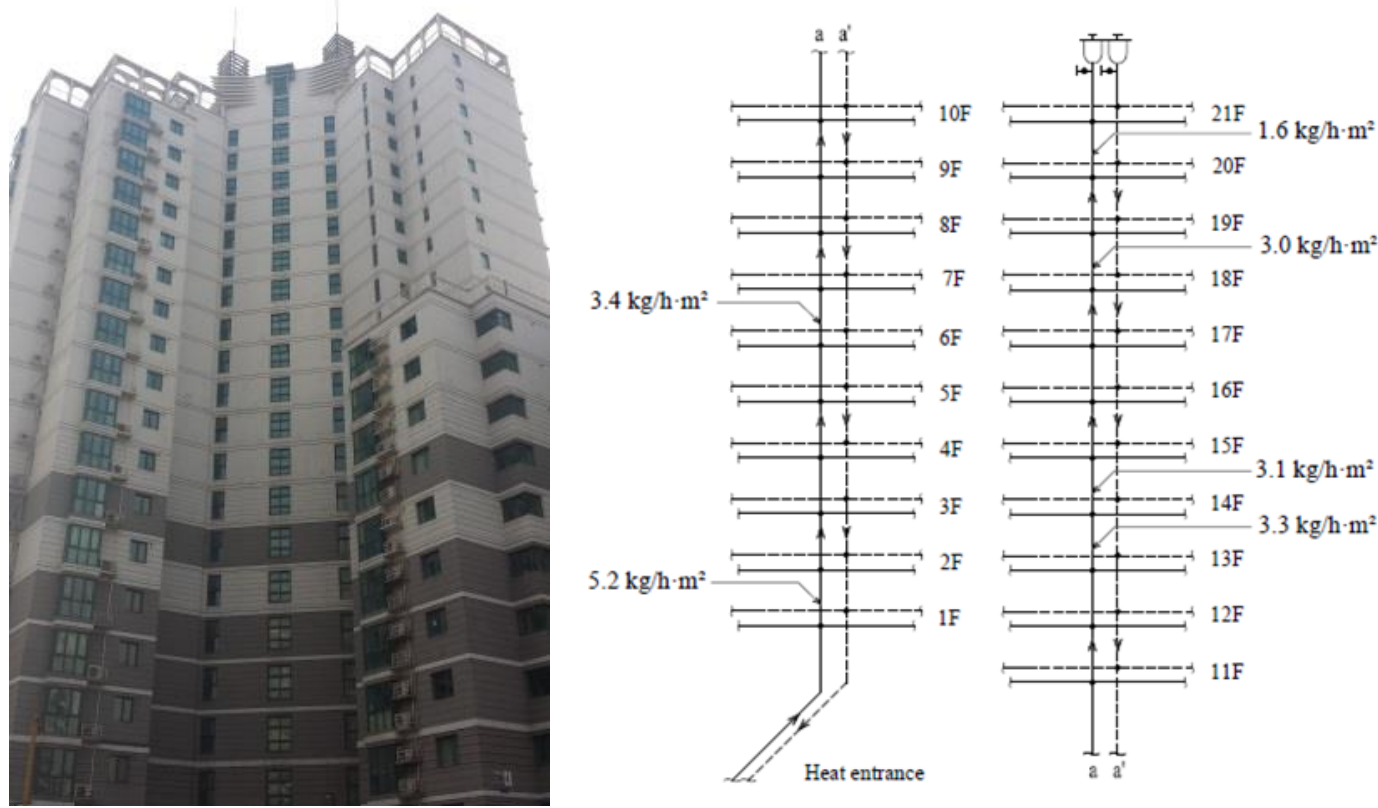

Figure 3. Building \#3's appearance and the mass flow along one of the vertical riser supplies(Zhang et al. 2016) 


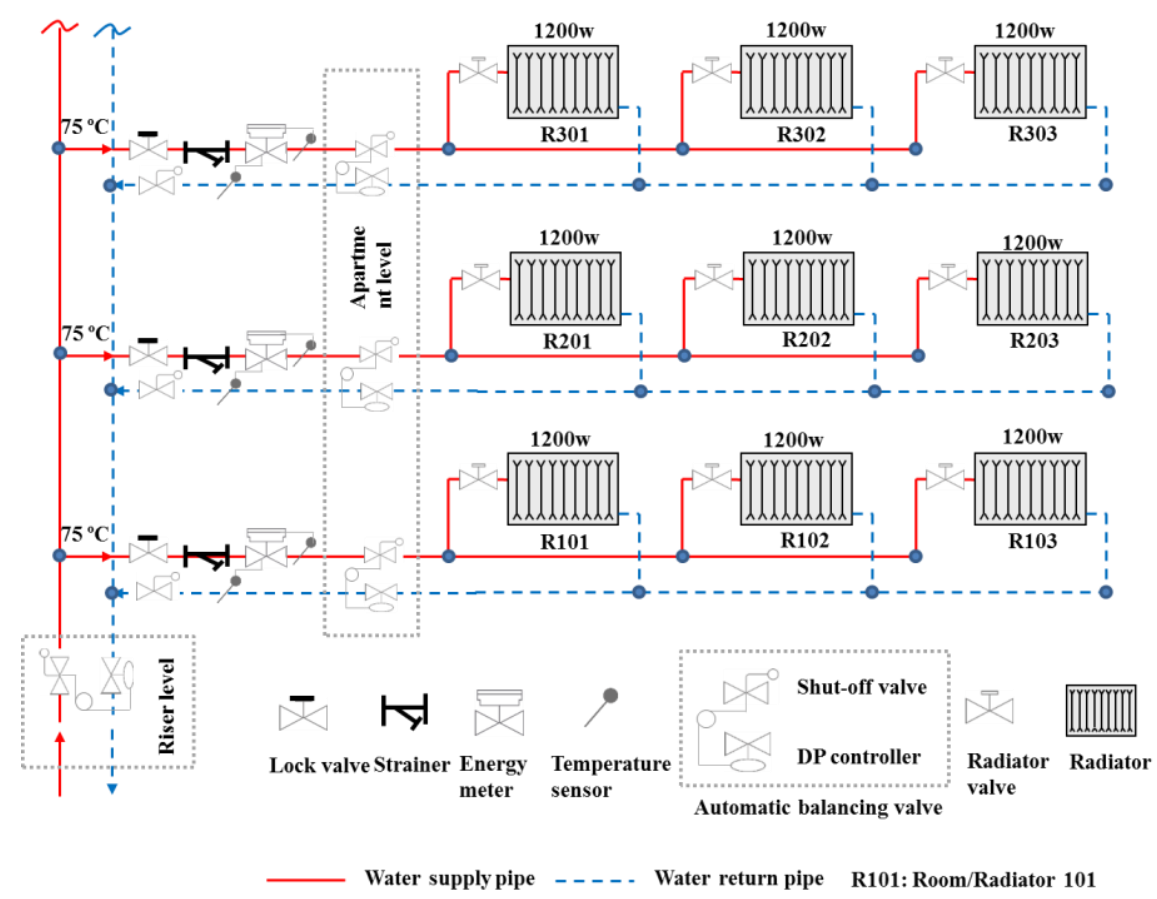

Figure 4. Schematic layout of the integrated model

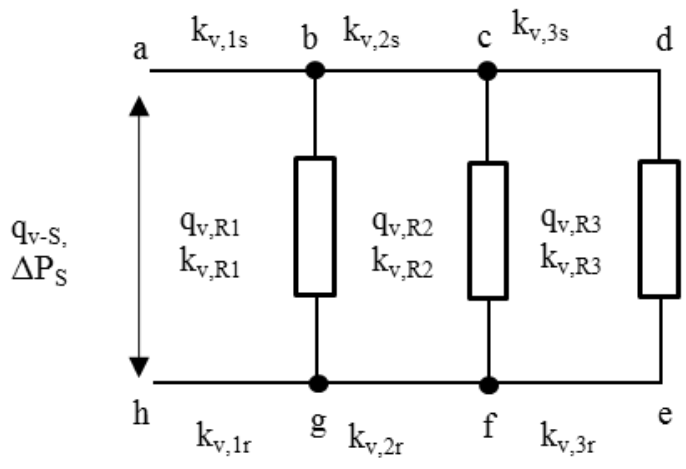

Figure 5. Mathematical model of hydraulic model 


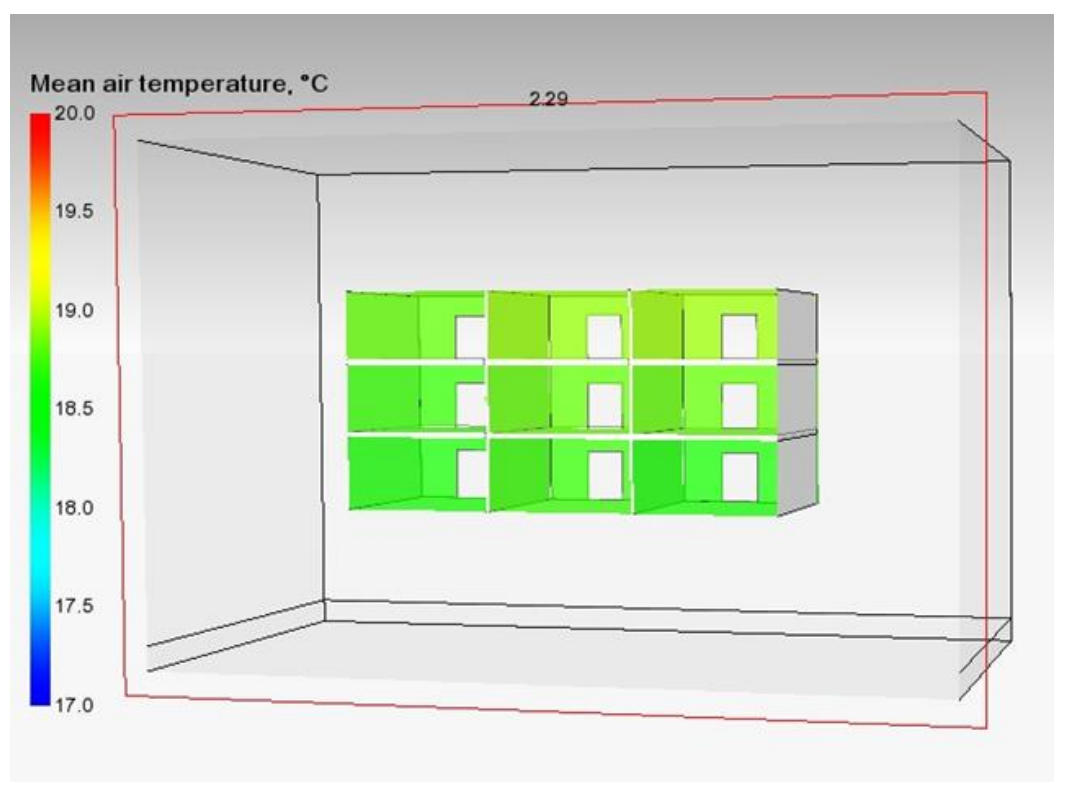

Figure 6. Mean air temperatures of all zones $\left({ }^{\circ} \mathrm{C}\right)$

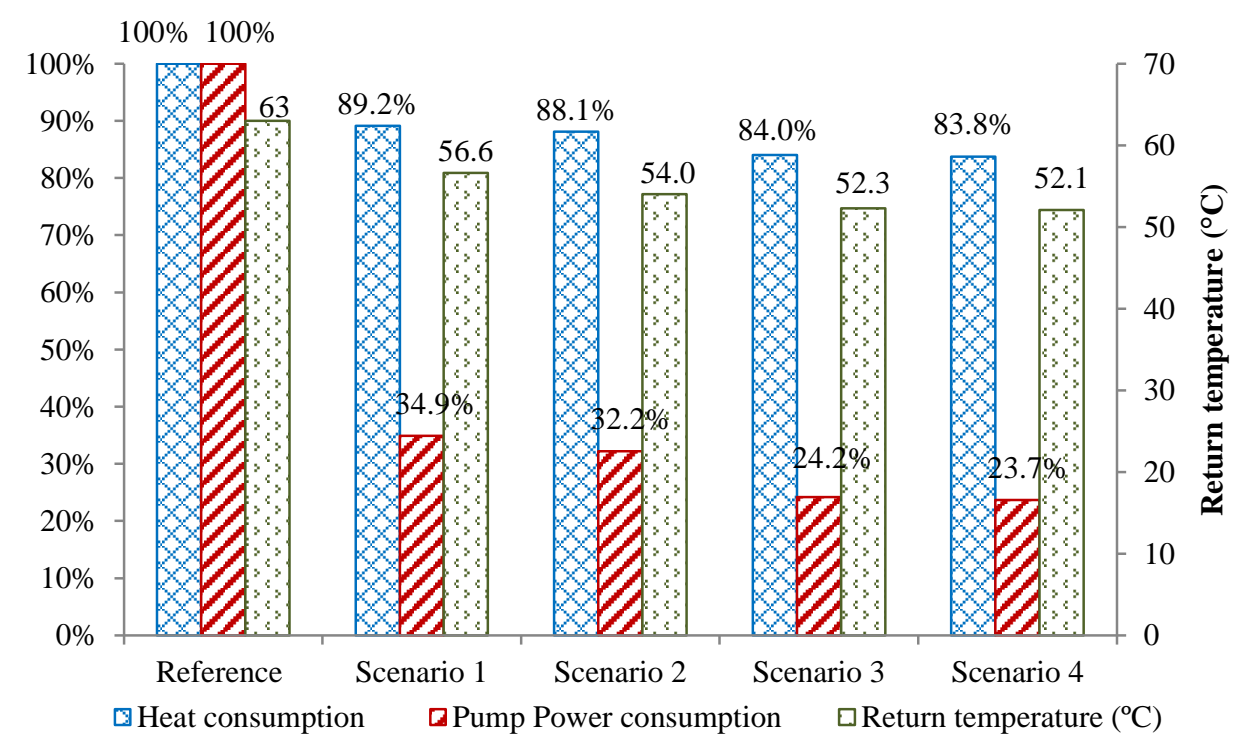

Figure 7. Comparison of the reference and the four scenarios 


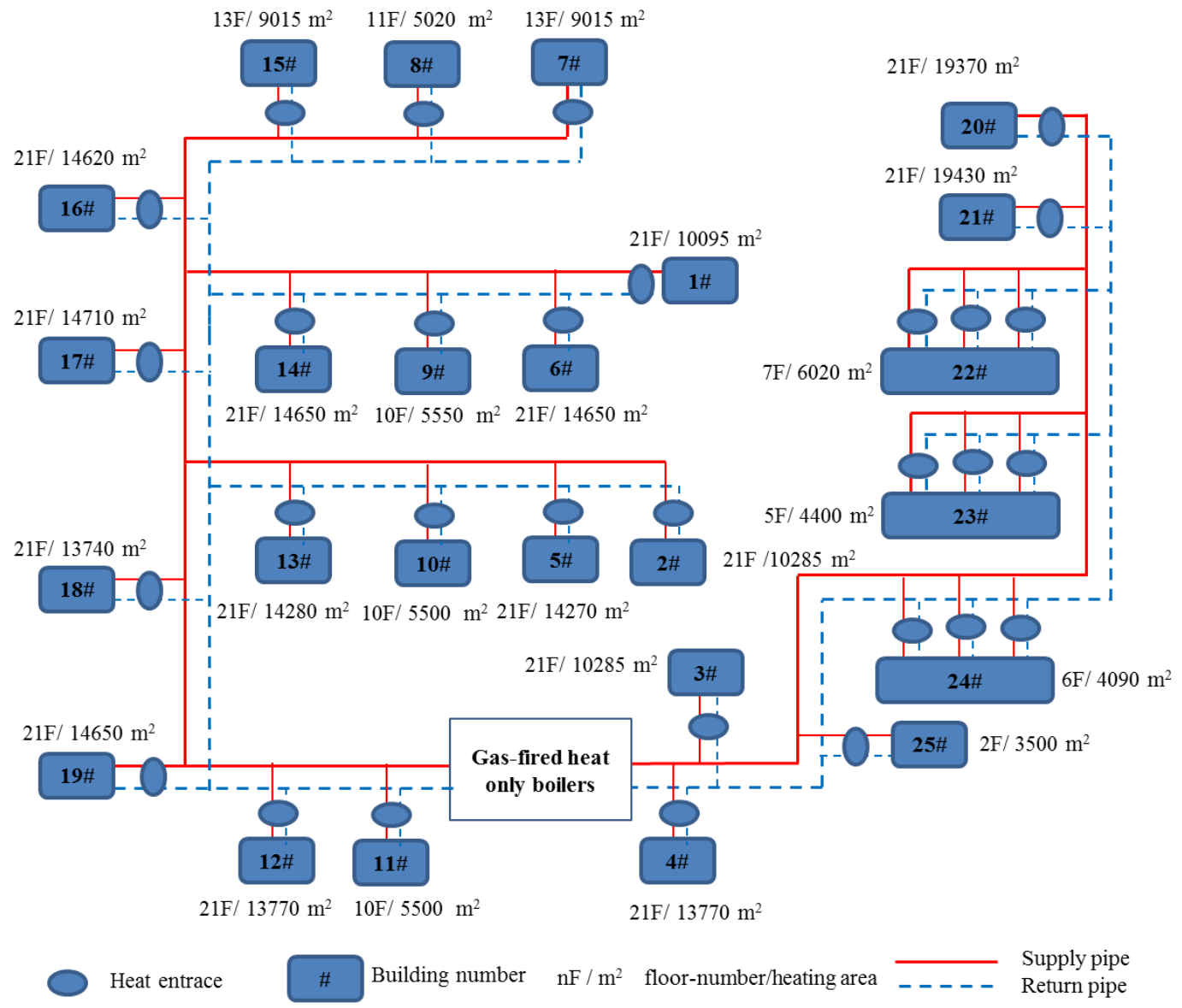

Figure 1. Heating system layout of CASE-Beijing 


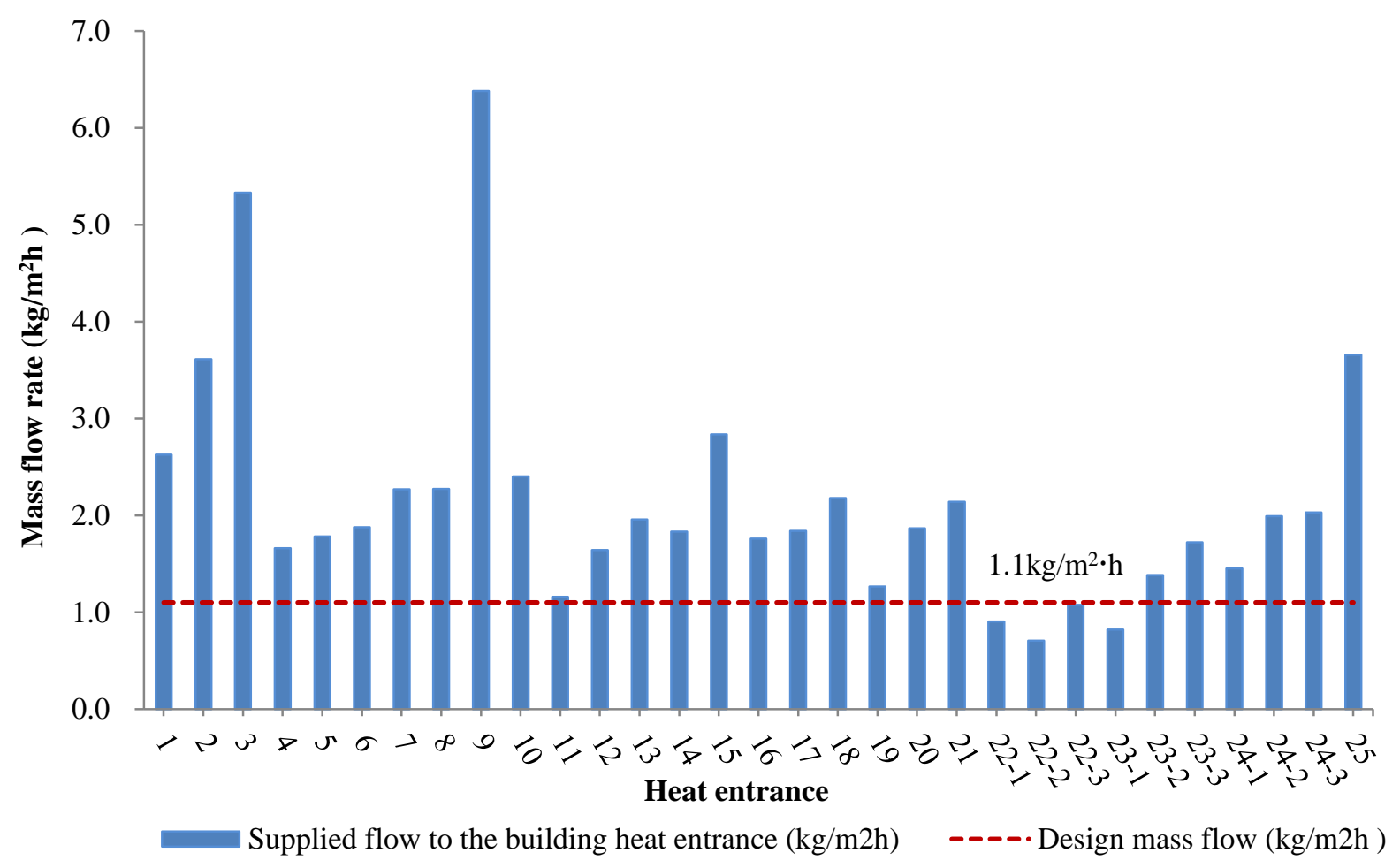

Figure 2. Mass flow of the 31 heat entrances of CASE-Beijing 


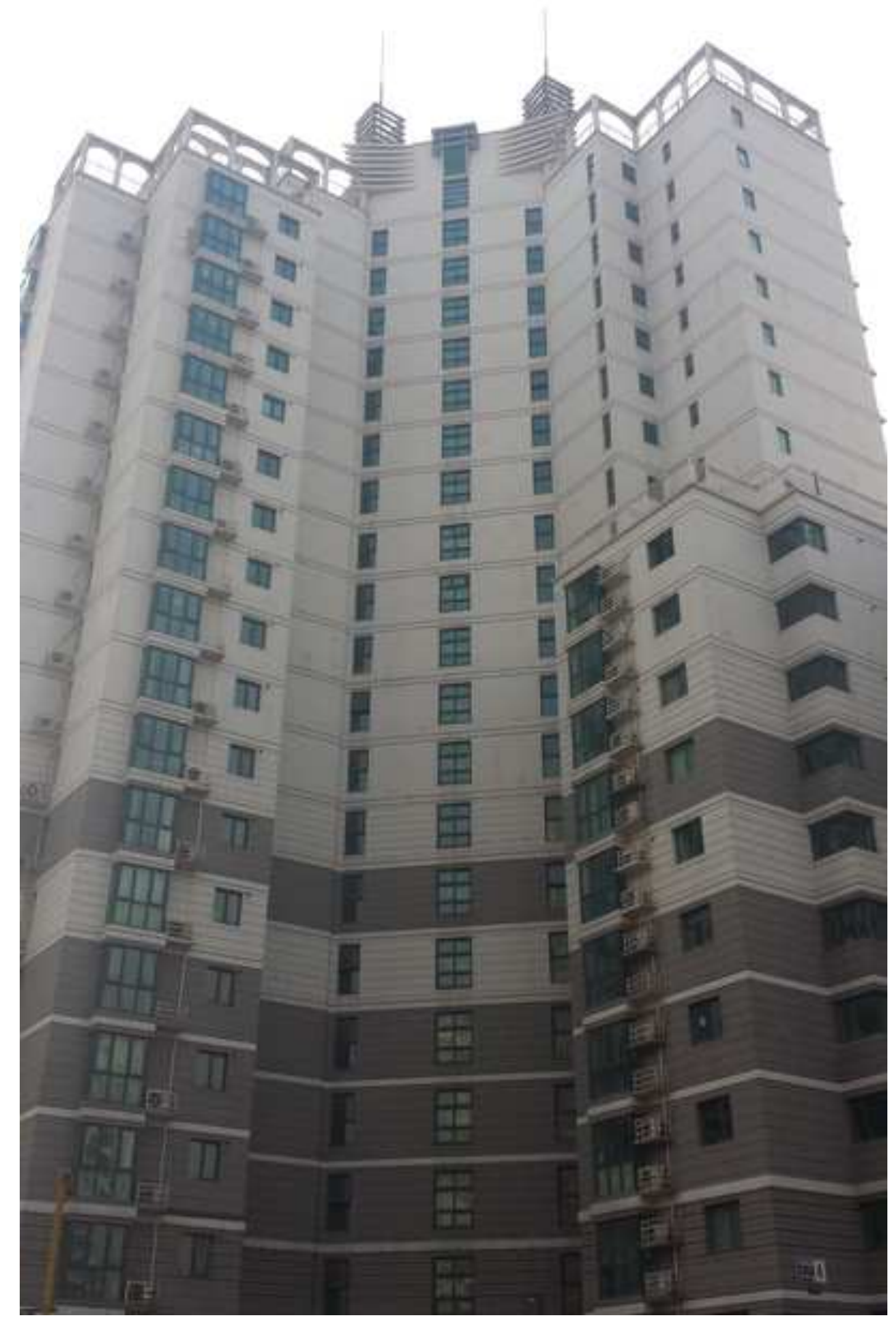



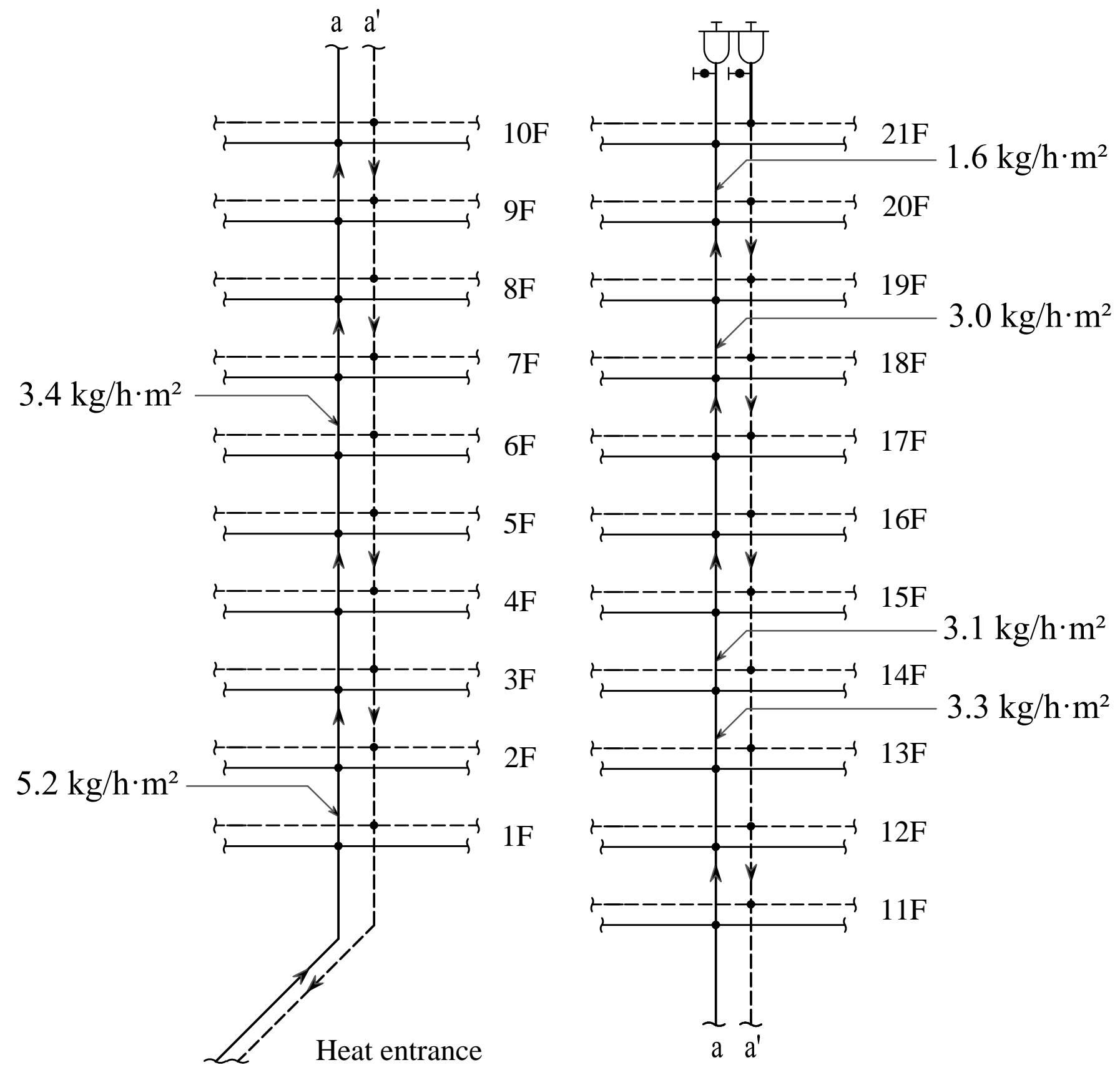


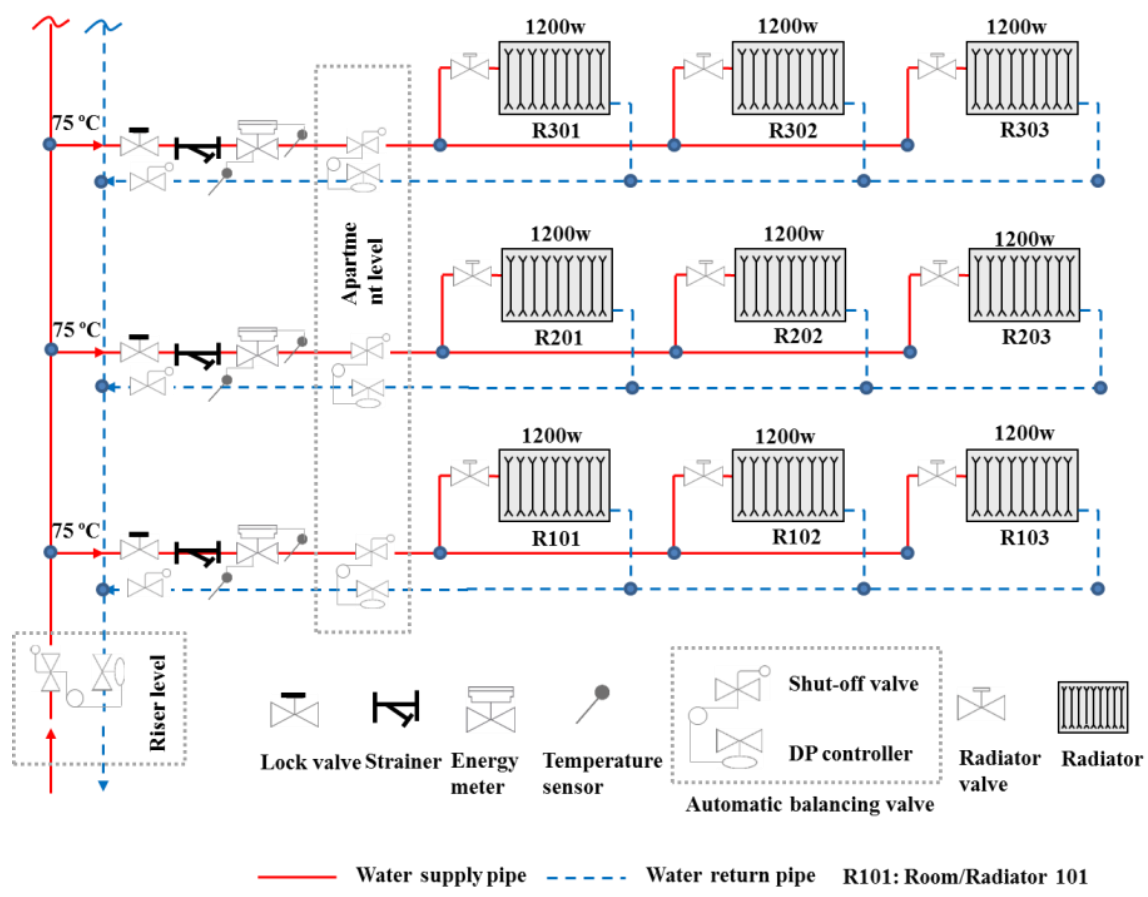

Figure 4. Schematic layout of the integrated model 


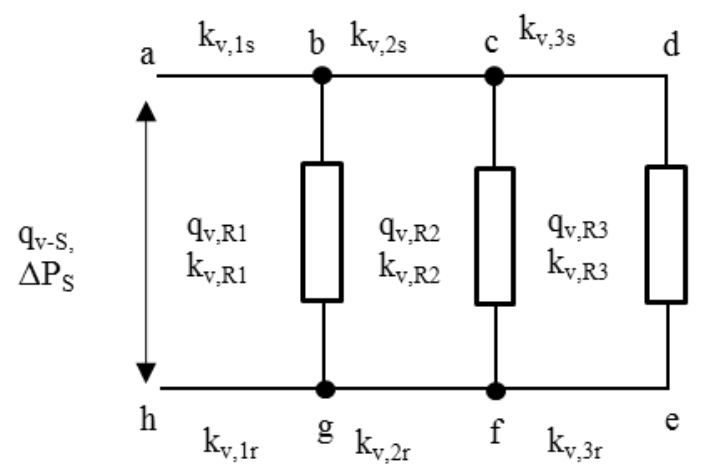

Figure 5. Mathematical model of hydraulic model 


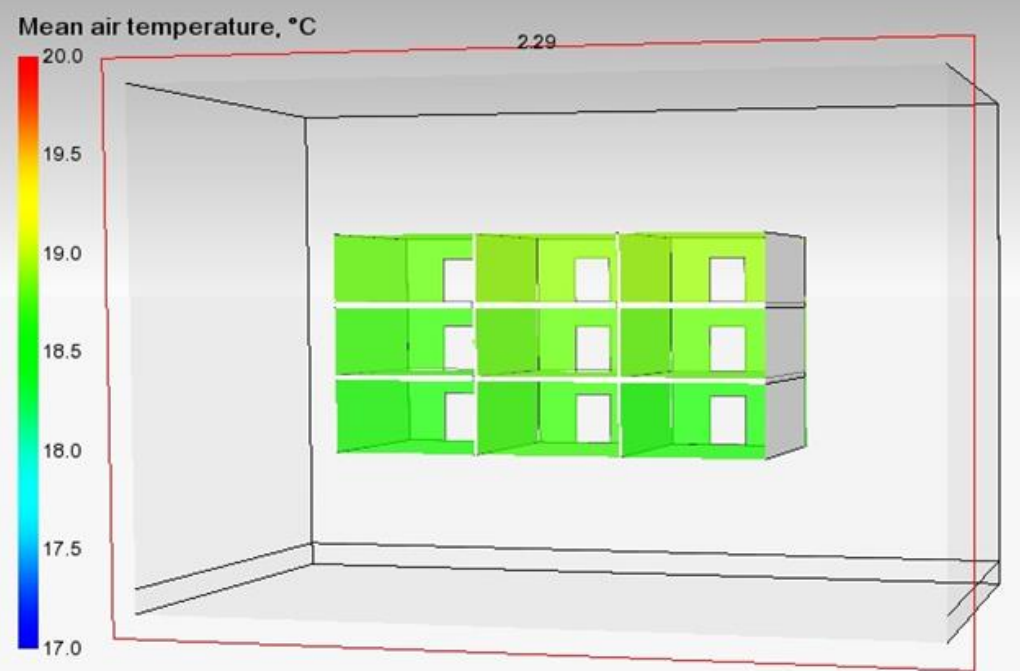

Figure 6. Mean air temperatures of all zones $\left({ }^{\circ} \mathrm{C}\right)$ 


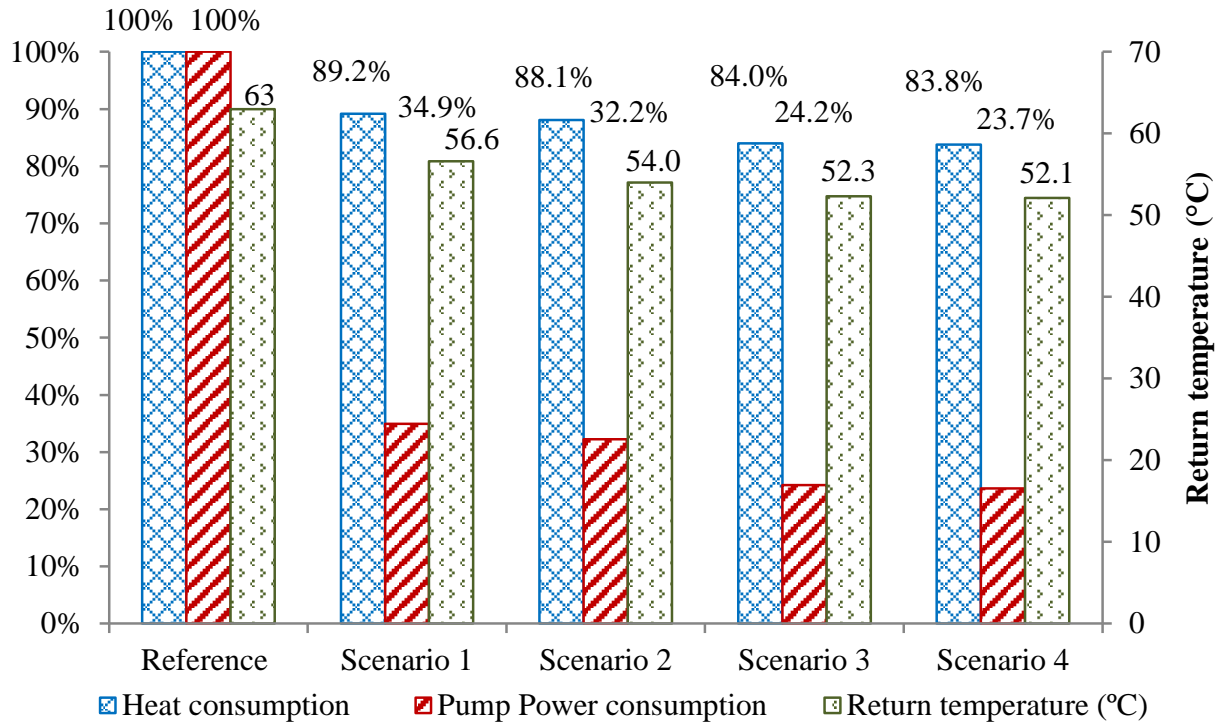

Figure 7. Comparison of the reference and the four scenarios 
Table 1. The reference and the four scenarios

\begin{tabular}{ccccccc}
\hline Control conditions & $\begin{array}{c}\text { No DP controllers, } \\
\text { just pipes }\end{array}$ & \multicolumn{2}{c}{$\begin{array}{c}\text { Apply DP controllers } \\
\text { Apartment } \\
\text { level }\end{array}$} & $\begin{array}{c}\text { No radiator valves, } \\
\text { just pipes }\end{array}$ & \multicolumn{2}{c}{ Apply radiator valve } \\
No pre-setting & With pre-setting \\
\hline Reference & $\sqrt{ }$ & - & - & $\sqrt{ }$ & - & - \\
Scenario 1 & - & $\sqrt{ }$ & - & - & $\sqrt{ }$ & - \\
Scenario 2 & - & - & $\sqrt{ }$ & - & - & $\sqrt{ }$ \\
Scenario 3 & - & $\sqrt{ }$ & - & - & - & $\sqrt{ }$ \\
Scenario 4 & - & - & $\sqrt{ }$ & - & & - \\
\hline
\end{tabular}


Table 2. The design flows and indoor temperatures for the building model

\begin{tabular}{lcccccccccc}
\hline Items & Radiator & Radiator & Radiator & Radiator & Radiator & Radiator & Radiator & Radiator Radiator & Total flow \\
& 101 & 102 & 103 & 201 & 202 & 203 & 301 & 302 & 303 & $(\mathrm{~kg} / \mathrm{h})$ \\
\hline Design flow $(\mathrm{kg} / \mathrm{h})$ & 41.3 & 41.3 & 41.3 & 41.3 & 41.3 & 41.3 & 41.3 & 41.3 & 41.3 & \\
Room temperature $\left({ }^{\circ} \mathrm{C}\right)$ & 18.7 & 18.8 & 18.7 & 18.8 & 18.9 & 18.9 & 18.9 & 19.0 & 19.0 & 371.3 \\
\hline
\end{tabular}


Table 3. Comparison of the simulation results for the reference and the four scenarios

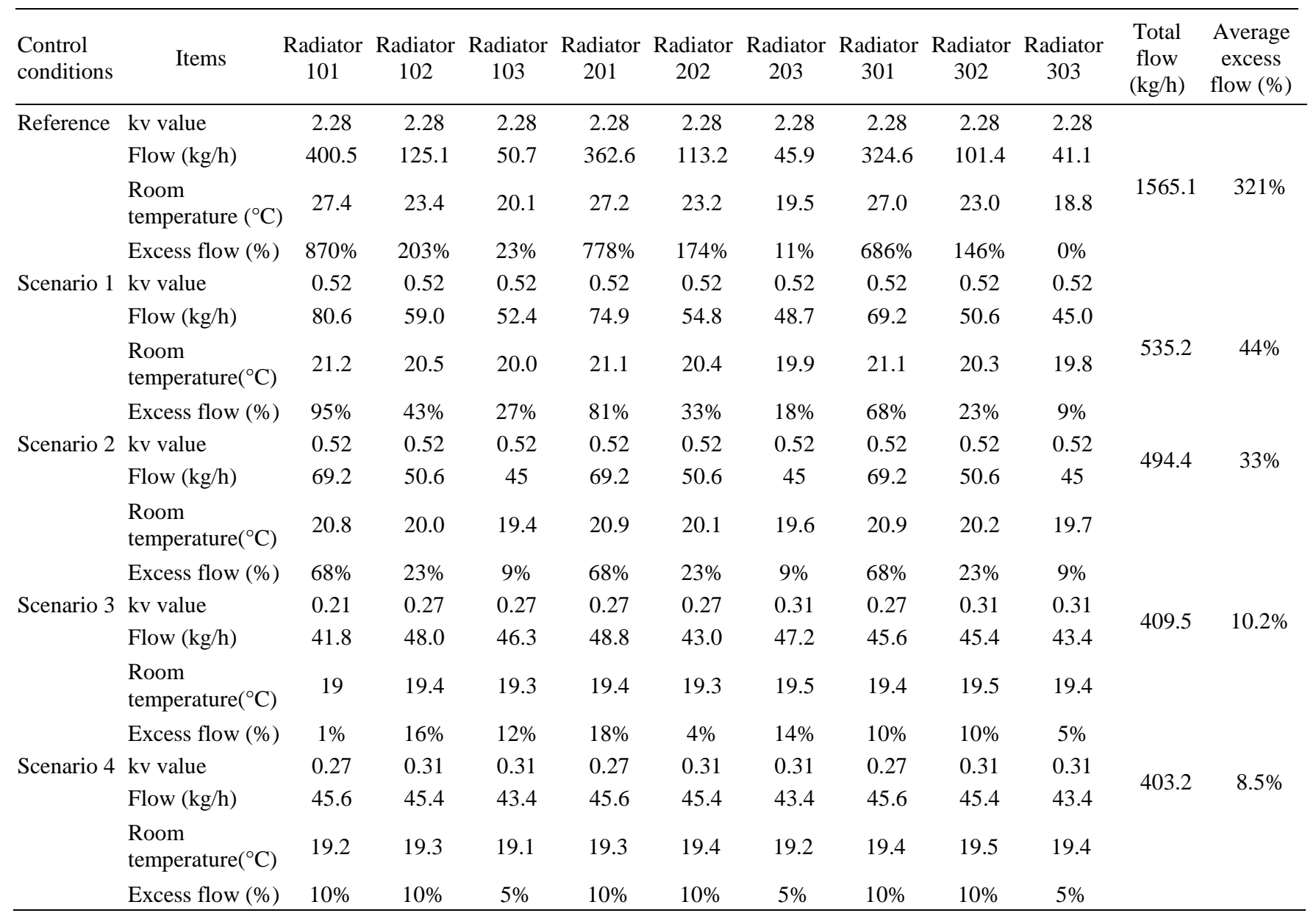


Click here to access/download
Supplementary Material
Full Manuscript.docx

Click here to access/download
Supplementary Material
Full Manuscript.docx Click here to access/download
Fupplementary Material Manuscript.docx
Full Mantols

.

and

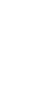

+

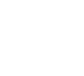

(1)

